\title{
Food Insecurity and Its Predictors among Lactating Mothers in North Shoa Zone, Central Ethiopia
}

Lemma Getacher ( $\square$ lemmagetacher@gmail.com )

Debre Berhan University https://orcid.org/0000-0002-9237-117X

\section{Gudina Egata}

Addis Ababa University

Yared Asmare Aynalem

Debre Berhan University

Abebaw Molla

Mizan Tepi University

Adane Tesfaye

Dilla University

Haimanot Abebe

Wolkitie University

Wubet Alebachew

Debre Tabor University

Samuel Derbie

Debre Markos University

\section{Research Article}

Keywords: Food Insecurity, Prevalence, Lactating Mothers, Predictors, Ethiopia

Posted Date: August 19th, 2020

DOI: https://doi.org/10.21203/rs.3.rs-61495/v1

License: (c) (i) This work is licensed under a Creative Commons Attribution 4.0 International License.

Read Full License 
Food Insecurity and Its Predictors among Lactating Mothers in North Shoa Zone, Central

Ethiopia

3 Lemma Getacher $^{1 *}$, Gudina Egata ${ }^{2}$, Yared Asmare Aynalem ${ }^{3}$, Abebaw Molla ${ }^{4}$, Adane Tesfaye ${ }^{5}$,

$4{\text { Haimanot } \text { Abebe }^{6} \text {, Wubet Alebachew }}^{7}$, and Samuel Derbie ${ }^{8}$

$5{ }^{1}$ Department of Public Health, College of Health Sciences, Institute of Medicine and Health

6 Sciences, Debre Berhan University, Debre Berhan, Ethiopia

$7{ }^{2}$ School of Public Health, College of Health Sciences, Addis Ababa University, Addis Ababa,

8 Ethiopia

$9{ }^{3}$ Department of Nursing, College of Health Sciences, Institute of Medicine and Health Sciences,

10 Debre Berhan University, Debre Berhan, Ethiopia

$11{ }^{4}$ Department of Nursing, College of Health Sciences, Mizan Tepi University, Mizan Tepi, 12 Ethiopia

135 Department of Nutrition, School of Public Health, College of Health Sciences, Dilla University, 14 Dilla, Ethiopia

$15{ }^{6}$ Department of Public Health, College of Medicine and Health Sciences, Wolkitie University, 16 Wolkitie, Ethiopia

$17{ }^{7}$ Department of Pediatrics and Neonatal Nursing, College of Health Sciences, Debre Tabor 18 University, Debre Tabor, Ethiopia

$19{ }^{8}$ Department of Public Health, College of Health Sciences, Debre Markos University, Debre 20 Markos, Ethiopia

\section{Email address of all authors;}

22 Lemma Getacher lemmagetacher@gmail.com, Gudina Egata gudina_egata@yahoo.com Yared

23 Asmare yaredasmare123@gmail.com, Abebaw Molla abebawmolla2001@gamil.com, Adane

24 Tesfaye adanetesfaye2006@gmail.com, Haimanot Abebe haimanotabebe78@gmail.com, Wubet

25 Alebachew wubetalebachew@gmail.com, Samuel Derbie kasadr21@gmail.com

26 *Corresponding Author: Lemma Getacher (BSc, MPH, PhD Fellow in Human Nutrition)

27 E-mail: lemmagetacher@gmail.com

28 Institutional email: lemmagetacher@ dbu.edu.et

29 Telephone number: +251921137096

30 P.O. Box: 445, Debre Berhan University, Debre Berhan, Ethiopia 


\section{ABSTRACT}

32 Background: Ending food insecurity is one of the goals of Sustainable Development Goals

33 (SDGs). It is also one of the serious problems of Ethiopia. However, there is a dearth of studies

34 that show the status of food insecurity among lactating mother in Ethiopia including the study area.

35 Therefore, the objective of this study is to assess the predictors of food insecurity among lactating

36 mothers in Ataye District, North Shoa, and Central Ethiopia.

37 Methods: A community-based cross-sectional study design was used among 612 lactating mothers

38 aged 15-49 years. The food insecurity was determined by computing nine standards Household

39 Food Insecurity Access Scale (HFIAS) questions. A structured interviewer-administered

40 questionnaire was used to collect the data. Data were entered into EpiData version 4.2 and exported

41 to SPSS (Statistical Package for Social Science) version 24 for analysis. Odds ratio with $95 \%$

42 confidence interval was used for the predictors of food insecurity using bivariable and

43 multivariable logistic regression analysis.

44 Results: The prevalence of food insecurity among lactating mothers was $36.8 \%$. No formal 45 education $[(\mathrm{AOR}=1.82,95 \% \mathrm{CL}:(1.13,2.92)]$, no income-generating activities $[(\mathrm{AOR}=3.39,95 \%$

46 CI: $((2.05,5.64))]$, no home gardening practices [(AOR=5.65, 95\% CI: $(3.51,9.08)]$, alcohol use

47 by husbands [(AOR=2.02, 95\% CI: $(1.25,3.24)]$, low minimum dietary diversity scores $48[(\mathrm{AOR}=2.94,95 \% \mathrm{CI}:(1.88,4.57)]$, less than three frequencies of meals $[(\mathrm{AOR}=3.97,95 \% \mathrm{CI}$ :

$49(1.65,9.54)]$ and three meals only per day $[(\mathrm{AOR}=1.86,95 \% \mathrm{CI}:(1.08,3.17)]$ were significant 50 predictors of food insecurity of mothers.

51 Conclusion: The prevalence of food insecurity was high in the study area. No formal education,

52 no income-generating activities, no home gardening practice, alcohol use by husbands, low

53 minimum dietary diversity score, fewer than three frequencies of meals and three meals only per 
54 day were independent predictors of food insecurity. Therefore, increasing home gardening,

55 decreasing alcohol intake, increasing dietary diversity, and performing income-generating

56 activities are highly recommended to reduce food insecurity.

57 Keywords: Food Insecurity, Prevalence, Lactating Mothers, Predictors, Ethiopia

\section{BACKGROUND}

59 Food Insecurity (FI) is a condition in which all people at all times do not have physical, social and

60 economic access to a sufficient, nutritious, and safe food to meet their dietary needs for a

61 productive, effective, and healthy life. It also exists when availability, quality, and quantity of

62 foods are limited or cannot be accessed in a socially acceptable manner that promotes and

63 maintains the health and wellbeing of individuals [1-5]. It can be classified as food secure, mildly

64 food insecure, moderately food insecure and severely food insecure $[2,6]$.

65 Currently, it has become a global challenge and affects all nations regardless of their wealth status,

66 but it is more severe and prevalent in low- and middle-income countries, especially in the past two

67 decades [7, 8]. Due to the worsening of global economic conditions, food insecurity has received

68 increased attention worldwide. The increment of food insecurity situation and the lack of progress

69 towards the World Health Organization (WHO) global nutrition targets make it imperative for

70 countries to step up their efforts and to create a world without hunger and malnutrition by 2030 [7,

\section{$71 \quad \mathbf{9}, \mathbf{1 0}]$.}

72 Lactating mothers need more nutritious and qualified food to satisfy their physical needs and their

73 child needs, because the requirements of calorie and essential nutrients are high during this period.

74 Despite the increased nutritional requirements, especially in Africa, particularly in Ethiopia,

75 lactating mothers are extremely vulnerable to both macronutrient and micronutrient deficiencies 
76 [11]. In the condition of food insecurity, mothers are more vulnerable to malnutrition. Food

77 insecurity, being a devastating problem, affects not only mothers but also their infants everywhere

78 in the globe $[7,11]$.

79 In several developing countries, including Ethiopia, achieving food security for all people at all

80 times remains a great challenge. Ethiopia, which has been plagued with food insecurity for

81 decades, is one of the world's poorest nations with indicators showing low levels of development

82 and increased conditions of malnutrition [9, 12-14].

83 In summary, the prevalence of food insecurity ranges from $17 \%$ to $83 \%$ in global countries

84 conducted from 2012 to 2018 [11, 15-19], from $31.3 \%$ to $91.0 \%$ in other African countries

85 conducted from 2013 to 2017 [10, 20-22] and from 6.8\% to 77\% in Ethiopia conducted from 2013

86 to $2016[\mathbf{9}, \mathbf{2 3}-27]$.

87 The major causes of food insecurity of mothers emerged from different sources such as lack of

88 formal education, rural residence, poor occupational status, large family size, increased number of

89 under-five children, absence of income-generating activities, poor dietary diversity practice and

90 low frequency of meals per day $[\mathbf{9}, \mathbf{1 2}, \mathbf{1 3}, \mathbf{2 4}, \mathbf{2 5}$. Notwithstanding that, the effect of home

91 gardening practices and alcohol use by their husbands on the food insecurity of mothers has not

92 been well addressed by previous studies.

93 Likewise, previous studies did not address lactating mothers' feelings of uncertainty or anxiety

94 over food, perceptions that food is of insufficient quantity, perceptions that food is of insufficient

95 quality, reported reductions in food intake, reported consequences of reduced food intake, and

96 feelings of shame for resorting to socially unacceptable means to obtain food resources for their

97 household members [1]. 
98 Moreover, most of the previous studies only addressed the feelings and perceptions of household

99 heads (mostly male), except for some studies that addressed the feelings and perceptions of

100 pregnant women. This indicates that there is a dearth of studies that need to address the feelings

101 and perceptions of lactating mothers on food insecurity.

102 In addition, most of the time in the Ethiopian context, mothers are responsible for preparing and

103 cooking food for all household members. This leads them to know well the presence or absence of

104 sufficient food for all members of the household. For this reason, lactating mothers are the best

105 respondents for food insecurity studies.

106 Furthermore, currently, there are limited findings on food insecurity in low-income countries like

107 Ethiopia among lactating mothers, including the study area. Therefore, the objective of this study

108 was to assess the prevalence of food insecurity and its predictors among lactating mothers

109 including factors that were not included by previous studies in Ataye District, North Shoa Zone,

110 Ethiopia.

\section{METHODS AND MATERIALS}

\section{Study Setting and Design}

113 This study was conducted in the Ataye District, which is $270 \mathrm{~km}$ away from Addis Ababa (the 114 capital city of Ethiopia) and $140 \mathrm{~km}$ from Debre Berhan Town (the Zonal Town of North Shoa) in 115 central Ethiopia. From the 2007 national census projection, the total population of Ataye District 116 was 110,493 , and the current population is estimated to be 170,425 . The district has 30 kebeles 117 which is the lowest administrative unit in Ethiopia (Ataye District report, 2017). This study was 118 conducted in two urban and four rural randomly selected kebeles of the District. 
119 A community-based cross-sectional study design was used to determine the prevalence and

120 predictors of FI from February to April, 2018. During the study period, the source populations of

121 the study were all lactating mothers aged 15 to 49 years.

122 Regarding the eligibility criteria, mothers aged 15 to 49 years who lived for at least six months

123 and above in the District were included. On the other hand, mothers who were unable to respond

124 to an interview, were severely sick and did not volunteer to respond to the questionnaire were 125 excluded from this study.

\section{Sample Size Determination and Sampling technique}

127 The required sample size for this study was determined and calculated using a single population 128 proportions formula with the following assumptions: proportion of food insecurity among lactating 129 mothers $50 \%(0.5), \mathrm{Z}_{\mathrm{a} / 2}$ with $95 \%$ confidence level to be 1.96 , margin of error to be 0.05 , non130 response to be $10 \%$, and a design effect of 1.5 . Accordingly, the final calculated sample size of the 131 study was 635.

132 Regarding the sampling procedures, considering kebele as clusters, lactating mothers in the 133 households were selected by the cluster sampling technique. Ataye District has 30 kebeles (6 urban 134 and 24 rural). However, the kebeles were selected using a simple random sampling method. Based 135 on the residence of mothers, these kebeles/clusters were classified into urban and rural areas. The 136 sample size was allocated proportionally according to the population size of the selected urban and 137 rural kebeles. The number of lactating mothers found in each kebele was taken from a family 138 folder, which is documented by the Health Extension Workers (HEWs) with respect to their 139 household. Through house-to-house visits, all lactating mothers in randomly selected clusters were 140 included in the study. During the absence of eligible mothers during the time of visit, a revisit was 
141 arranged with a minimum of three times and finally if they were not presently considered non142 respondents.

\section{Data Collection Methods and Instruments}

144 The study data collection instruments were developed by reviewing different kinds of literature 145 using the search engines such as PubMed, Google Scholar, Hinari, and The Lancet series. A

146 structured interviewer-administered questionnaire was used to collect the data through Amharic 147 language (local language), which was translated from English language.

148 The data collectors of this study were six female grade ten graduated students who were fluent

149 speakers in the local language. The data collectors underwent a community-based face-to- face 150 interview using a structured and pretested Amharic questionnaire. The interviewers were informed 151 of the lactating mothers about all the details of the research. Two-degree health professionals from 152 Ataye District Hospital and Health Center were recruited for the supervision of the data collection 153 procedure.

154 The variables of this study were grouped as sociodemographic variables, health service utilization 155 related variables and food source and feeding practice of mother-related variables. The 156 sociodemographic variables were place of residence, maternal age, marital status, maternal 157 educational status, family size, number of under-five, maternal occupation, religion, ethnicity, and 158 sex of household head. The health service utilization related variables were ANC visit, place of 159 delivery, PNC visit, and maternal history of illness. The food source and feeding practice of 160 mothers' related variables were inadequate dietary intake, nutrition knowledge, sources of food, 161 home gardening practice, alcohol intake by husbands, and income generating activities.

\section{Measurements and Operational Definitions}


163 Household food insecurity was measured with the Household Food Insecurity Access Scale 164 (HFIAS), a structured, standardized, and validated tool that developed mainly by FANTA, to 165 classify households as food secure or not $[\mathbf{1 , 2 8}]$. The scale is a valid tool for measuring household 166 food insecurity among both rural and urban areas of Ethiopia with Cronbach's alpha values of 0.76 167 for round 1 and 0.73 for round 2 [29].

168 Lactating mothers: In this study, mothers were aged 15-49 years and had 6-23-month-old 169 children who were currently feeding breast milk for her infant/child (30).

170 Food secure mothers: Mothers who experience none of the food insecurity (access) conditions or 171 just experience worry, but rarely in the past 4 weeks (6).

172 Food insecure mothers: Mothers who experience inability to access sufficient food at all times 173 to lead an active and healthy life (includes all stages of food insecurity; mild, moderate and severe) $174(6)$.

175 Mildly food insecure mothers: Mothers who worry about not having enough food sometimes or 176 often and/or are unable to eat preferred foods and/or eat a more monotonous diet than desired 177 and/or some foods considered undesirable, but only rarely (6).

178 Moderately food insecure mothers: Mothers who sacrifice quality more frequently, by eating a 179 monotonous diet or undesirable foods sometimes or often, and/or have started to cut back on 180 quantity by reducing the size of meals or number of meals, rarely or sometimes. However, it does 181 not experience any of the three most severe conditions (6).

182 Severely food insecure mothers: Mothers who have forced cutting back on meal size or number 183 of meals often and/or experience any of the three most severe conditions (running out of food, 184 going to bed hungry, or going a whole day and night without eating), even as infrequently as rarely 185 (6). 


\section{Data Quality Control}

187 The data collection instrument was translated back to English by independent language experts in 188 both languages to ensure its consistency, and comparisons were made on the consistency of the 189 two versions. Before the actual data collection, the questionnaire was pretested outside the selected 190 kebeles on $5 \%$ of the total sample size to ensure the validity of the tool. After the pretest had done,

191 all the necessary adjustments were made. Some of the adjustments were the questions related to 192 knowledge of nutrition, the approaches of the data collectors and the ability to review the mothers 193 were further modified and improved. Then, the translated, pretested, and structured Amharic 194 version of the questionnaire was used to collect the data.

195 For the six female grade ten graduated students and the two supervisors, two days of training was 196 given on both theoretical and practical aspects. The focus area of training was about interview 197 techniques, ethical issues, rights of the participants, reading through all the questions and 198 understanding them well, and ways of minimizing under/over-reporting and maintaining 199 confidentiality.

200 Interviews were conducted in an area with adequate confidentiality, privacy, and without the 201 involvement of any other person other than the respondent. During the actual data collection, close 202 supervision was made by the principal investigator and the two supervisors. The collected data 203 were cross-checked on each day of activity for consistency, missing data, and completeness.

\section{Data Processing and Analysis}

205 The authors visually checked all the interviewed questionnaires before directly going to analysis. 206 EpiData version 4.2.0.0 software was used to code, enter, and clean the data. To cross-check the 207 data for completeness, double data entry was made by two data clerks. After doing this, the entered 208 data were exported and analyzed with Statistical Package for Social Science (SPSS) version 24 
209 software for windows using IBM SPSS Statistics 24 Core System User's Guide. To describe the

210 demographic, socioeconomic, and maternal-related characteristics of the respondents, simple

211 descriptive statistics such as simple frequency distribution, measures of central tendency, measures

212 of variability, and percentages were performed. Tables and figures were used to present the

213 information of respondents.

214 The outcome variable (food insecurity) was determined by computing nine standard household 215 Food Insecurity Access Scale (HFIAS) questions adapted from the FANTA (Food and Nutrition

216 Technical Assistance) project. The tool consists of nine questions that show frequency-of-

217 occurrence and measures the severity of food insecurity in the last four weeks in terms of Likert

218 Scale question responses $[0=$ never, $1=$ rarely (once or twice), $2=$ sometimes (three to ten times),

$2193=$ often (more than ten times)]. The mothers were expected to answer these questions on behalf

220 of all household members in their household. This tool was used to assess access to food for all

221 household members at the time of data collection. To determine the cumulative score of food

222 insecurity among mothers, the nine items ranged from 0-27, and a higher score indicated that the

223 household members experienced more food insecurity.

224 For analysis, all "Yes" responses were coded in "1" and "No" responses were coded in " 0 ", and

225 the responses were summed to obtain the household food insecurity status. The HFI status, which

226 had a high internal consistency (Cronbach's alpha = 0.927), was further dichotomized as “food

227 insecure" and "food secure" household, which were coded as " 1 " and "0", respectively, for 228 analysis.

229 The knowledge of mothers about nutrition was assessed and computed based on six questions

230 using a mean score. The questions include about the awareness of mothers about nutrition, dietary

231 diversity practice and taking varieties of food groups, types of varieties of food groups, definitions 
232 of the term varieties food groups, definitions of the term malnutrition, causes of malnutrition and

233 consequences of malnutrition. Mothers who scored above the mean cut-off point were considered

234 to have good knowledge and coded as "1", whereas those who scored below this cut-off point

235 were considered to have poor knowledge and coded as " 0 ".

236 To see the association between each independent variable and the outcome variable, the bivariate

237 analysis and crude odds ratio along with a 95\% confidence interval (CI) were used. In addition,

238 independent variables with a $\mathrm{P}$ value of $\leq 0.25$ were included in the multivariate analysis to control

239 for confounding factors.

240 To see the linear correlation among the independent variables, multicollinearity was checked using

241 standard error (SE). Variables with a standard error of $\geq 2$ were dropped from the multivariate

242 analysis. Hosmer-Lemeshow's goodness-of-fit model test coefficient was used to test the fitness

243 of the model which was found to be insignificant with a large $\mathrm{P}$ value $(\mathrm{P}=0.860)$.

244 To identify the predictors of food insecurity, adjusted odds ratios along with 95\% CIs were 245 estimated using multivariate logistic regression analysis. All tests were two-sided and the level of 246 statistical significance was declared at a $\mathrm{P}$ value less than 0.05 .

\section{RESULTS}

\section{Sociodemographic Characteristics of Respondents}

249 Out of 635 respondents, 612 responded to the interview resulting in a response rate of $96.23 \%$.

250 The nonparticipation was due to the absence of study participants during different visits at the time

251 of data collection. The mean age of mothers $( \pm$ SD) was $30.61( \pm 6.44)$ years. Of the total mothers,

$252398(65 \%)$ were rural by residence, $331(54.1 \%)$ were in the age group of 15-30, $526(85.9 \%)$ were

253 Orthodox Tewahido Christian by religion, 547 (89.4\%) were Amhara by ethnicity, 482 (78.8\%) 
254 were married by their marital status, $494(80.7 \%)$ were male household heads, $250(40.8 \%)$ had 255 no formal education and $374(61.1 \%)$ were housewives by their occupation (Table 1).

256 Table 1: Sociodemographic characteristics of respondents in Ataye District, $2018(n=612)$

\begin{tabular}{|c|c|c|}
\hline Variables & Category & Frequency $(\%)$ \\
\hline \multirow[t]{2}{*}{ Residence } & Urban & $214(35)$ \\
\hline & Rural & $398(65)$ \\
\hline \multirow[t]{3}{*}{ Age } & $15-30$ & $331(54.1)$ \\
\hline & $31-45$ & $274(44.8)$ \\
\hline & $>45$ & $7(1.1)$ \\
\hline \multirow[t]{4}{*}{ Ethnicity } & Amhara & $547(89.4)$ \\
\hline & Oromo & $49(8.0)$ \\
\hline & Tigrai & $11(1.8)$ \\
\hline & Others & $5(0.8)$ \\
\hline \multirow[t]{3}{*}{ Religion } & Orthodox Tewahido Christian & $526(85.9)$ \\
\hline & Muslim & $47(7.7)$ \\
\hline & Protestant & $39(6.4)$ \\
\hline \multirow[t]{5}{*}{ Marital status } & Single & $39(6.4)$ \\
\hline & Married & $482(78.8)$ \\
\hline & Divorced & $54(8.8)$ \\
\hline & Widowed & $26(4.2)$ \\
\hline & Separated & $11(1.8)$ \\
\hline \multirow[t]{2}{*}{ Sex of household head } & Male & $494(80.7)$ \\
\hline & Female & $118(19.3)$ \\
\hline \multirow[t]{5}{*}{ Educational status } & No formal education & $250(40.8)$ \\
\hline & Read and write & $133(21.7)$ \\
\hline & Primary education & $98(16)$ \\
\hline & Secondary education & $51(8.3)$ \\
\hline & More than secondary education & $80(13.1)$ \\
\hline Occupational status & Housewife & $374(61.1)$ \\
\hline
\end{tabular}




\begin{tabular}{lll}
\hline & Merchant & $74(12.1)$ \\
& Daily laborer & $54(8.8)$ \\
& Government employee & $54(8.8)$ \\
& Self-employed & $52(8.5)$ \\
& Others & $4(0.7)$ \\
Family size & $1-3$ & $131(21.4)$ \\
& $4-6$ & $339(55.4)$ \\
Number of under 5 children & $>6$ & $142(23.2)$ \\
& $1-2$ & $580(94.8)$ \\
& $>2$ & $32(5.2)$ \\
\hline
\end{tabular}

\section{Health Service Utilization of Mothers}

258 More than half of mothers (56.9\%) had ANC visits greater than or equal to four visits. On the other 259 hand, nearly half of the mothers (47.9\%) delivered in the Health Center and $46.7 \%$ of them had 260 postnatal care follow-up. Three-tenths of mothers had an illness in the last 2 weeks (Table 2).

261 Table 2: Health service utilization of mothers in Ataye District, $2018(\mathrm{n}=612)$

\begin{tabular}{lll}
\hline Variables & Category & Frequency (\%) \\
\hline Number of ANC visits & No visit & $106(17.3)$ \\
& $\leq$ three & $348(56.9)$ \\
& $\geq$ four & $158(25.8)$ \\
Place of delivery & Home & $201(32.8)$ \\
& Health center & $293(47.9)$ \\
& Hospital & $118(19.3)$ \\
Postnatal care follow-up & Yes & $286(46.7)$ \\
Presence of illness in the last 2 weeks & No & $326(53.3)$ \\
& Nes & $180(29.4)$ \\
& No & $432(70.6)$ \\
\hline
\end{tabular}

\section{Food Source and Feeding Practice of Mothers}


263 The main source of food for the mothers was their own production, 346 (56.5\%). Nearly three-

264 fifths of mothers had home gardening practice in their yard. In addition, more than two-thirds of $265(68.8 \%)$ mothers had three frequencies of meals per day. Regarding the knowledge of nutrition, 266 minimum dietary diversity score, and income-generating activity, 344 (56.2\%), 308 (50.3), and 267346 (56.5) had good knowledge, high MDD score, and income-generating activity respectively 268 (Table 3).

269 Table 3: Food source and feeding practice of mothers in Ataye District, $2018(\mathrm{n}=612)$

\begin{tabular}{lll}
\hline Variables & Category & Frequency (\%) \\
\hline Source of food & Own production & $346(56.5)$ \\
& Purchasing & $256(41.8)$ \\
& Food aid/relief & $8(1.3)$ \\
Home gardening practice & Other sources & $2(0.3)$ \\
& Yes & $352(57.5)$ \\
Use alcohol & No & $260(42.5)$ \\
Meal frequency & Yes & $171(27.9)$ \\
No & Less than three meals & $441(72.1)$ \\
Thowledge of nutrition & Three meals & $47(7.7)$ \\
& Above three meals & $421(68.8)$ \\
Minimum dietary diversity score & Low ( $\leq 5$ food groups) & $144(23.5)$ \\
& High $(\geq 5$ food groups) & $268(43.8)$ \\
& Yes & $344(56.2)$ \\
& No & $304(49.7)$ \\
& & $308(50.3)$ \\
& Good & $346(56.5)$ \\
& & $266(43.5)$ \\
\hline
\end{tabular}


271 Of the nine HFIAS items, worry about food (37.3\%), unable to eat preferred foods (30.9\%) and

272 eat just a few kinds of foods $(22.5 \%)$ were the most frequently reported occurrences of food

273 insecurity items in mothers (Table 4).

274 Table 4: Descriptions of the nine (9) items of HFIAS food access questions of mothers in Ataye

275 District, $2018(\mathrm{n}=612)$

\begin{tabular}{lccccc}
\hline HFIAS 9 items & \multicolumn{3}{l}{ Response (\%) } & \multicolumn{3}{l}{ Frequency of occurrence (\%) } \\
\cline { 2 - 6 } & Yes & No & Rarely & Sometimes & Often \\
\hline Worry about food & 37.3 & 62.7 & 22.5 & 10.1 & 4.7 \\
Unable to eat preferred foods & 30.9 & 69.1 & 17.8 & 8.5 & 4.6 \\
Eat just a few kinds of foods & 22.5 & 77.5 & 16.8 & 3.8 & 1.9 \\
Eat foods they really do not want eat & 20.4 & 79.6 & 9.8 & 5.9 & 4.7 \\
Eat a smaller meal & 12.4 & 87.6 & 8.3 & 3.4 & 0.7 \\
Eat fewer meals in a day & 8.5 & 91.5 & 5.7 & 2.6 & 0.2 \\
No food of any kind in the household & 5.2 & 94.8 & 3.1 & 2.0 & 0.2 \\
Go to sleep hungry & 4.4 & 95.6 & 2.6 & 1.8 & 0.2 \\
Go a whole day and night without eating & 3.1 & 96.9 & 2.1 & 0.5 & 0.5 \\
\hline
\end{tabular}

276 In this study, more than three-fifths of mothers, $387(63.2 \%)$ were food secure whereas, 225

277 (36.8\%) were food insecure (Figure 1).

\section{Predictors of Food Insecurity among Mothers}

279 In the bivariate logistic regression analysis, sex of household head, educational status, number of

280 children under 5, alcohol use, income-generating activities, postnatal follow-up, main source of

281 food, home gardening practice, meal frequency, knowledge of nutrition, and minimum dietary 
282 diversity score were associated with food insecurity of mothers and became candidates for further

283 multivariate analysis (Table 5).

284 Using the enter method, those variables with a $\mathrm{P}$ value of $\leq 0.25$ in the bivariate logistic regression 285 analysis were entered into a multivariate logistic regression analysis to identify the independent 286 predictors of food insecurity. Accordingly, no formal education, alcohol use by husbands, no 287 income-generating activities, no home gardening practice, low minimum dietary diversity score, 288 and meal frequency less than three and three meals only were the significant predictors of food 289 insecurity of mothers (Table 5).

290 Mothers who had no formal education were 1.82 times [(AOR $=1.82$, 95\% CL: $(1.13,2.92)]$ more 291 likely to have food insecurity than those who had formal education. Regarding income-generating 292 activities, mothers who had no income-generating activities were 3.39 times [ $(\mathrm{AOR}=3.39,95 \%$ 293 CI: $(2.05,5.64)]$ more likely to be food insecure than their counterparts (Table 5).

294 On the other hand, the odds of food insecurity were 5.65 times higher among mothers who had no 295 home gardening practice $[(\mathrm{AOR}=5.65,95 \% \mathrm{CI}:(3.51,9.08)]$ than their counterparts. Lactating 296 mothers who had a husband who used alcohol in the last time were approximately 2.02 [(AOR = $2972.02,95 \%$ CI: $(1.25,3.24)]$ times more likely to have food insecurity status than their counterparts 298 (Table 5).

299 The odds of food insecurity were nearly three times $[(\mathrm{AOR}=2.94,95 \%$ CI: $(1.88,4.57)]$ more 300 common among mothers who had low minimum dietary diversity scores than among mothers who 301 had high minimum dietary diversity scores (Table 5).

302 Concerning the meal frequency of mothers, mothers who had less than three meals and three meals 303 only were 3.97 and 1.86 times more likely to be food insecure than those who had four meals and 
304 above $[(\mathrm{AOR}=3.97,95 \% \mathrm{CI}:(1.65,9.54)]$ and $[(\mathrm{AOR}=1.86,95 \% \mathrm{CI}:(1.08,3.17)]$, respectively 305 (Table 5).

306 Table 5: Bivariable and multivariable logistic regression ${ }^{1}$ analysis of predictors of food insecurity 307 among lactating mothers in Ataye district, $2018(n=612)$.

\begin{tabular}{|c|c|c|c|c|}
\hline \multirow[t]{2}{*}{ Variables } & \multicolumn{2}{|c|}{ Food security status } & \multirow[t]{2}{*}{ COR $(95 \%$ CI $)$} & \multirow[t]{2}{*}{$\operatorname{AOR}(95 \%$ CI $)$} \\
\hline & Insecure $(\%)$ & Secure $(\%)$ & & \\
\hline \multicolumn{5}{|l|}{ Sex of household head } \\
\hline Male & $190(35.5)$ & $304(61.5)$ & 1.00 & 1.00 \\
\hline Female & $35(29.7)$ & $83(70.5)$ & $0.67(0.44,1.04)$ & $0.80(0.46,1.38)$ \\
\hline \multicolumn{5}{|c|}{ Educational status of mothers } \\
\hline No formal education & $167(49.4)$ & $171(50.6)$ & $3.64(2.54,5.21) *$ & $1.82(1.13,2.92) *$ \\
\hline Formal education & $58(21.2)$ & $216(78.8)$ & 1.00 & 1.00 \\
\hline \multicolumn{5}{|c|}{ Number of $<5$ children } \\
\hline $1-2$ & $209(36)$ & $371(64)$ & 1.00 & 1.00 \\
\hline$>2$ & $16(50)$ & $16(50)$ & $1.77(0.87,3.62)$ & $1.45(0.57,3.67)$ \\
\hline \multicolumn{5}{|l|}{ Source of food } \\
\hline Own source & $160(46.2)$ & $186(53.8)$ & 1.00 & 1.00 \\
\hline No known source & $65(24.4)$ & $201(75.6)$ & $2.66(1.87,3.77)$ & $1.05(0.60,1.85)$ \\
\hline \multicolumn{5}{|c|}{ Income-generating activities } \\
\hline Yes & $81(23.4)$ & $256(76.6)$ & 1.00 & 1.00 \\
\hline No & $144(54.1)$ & $122(45.9)$ & $3.86(2.73,5.46) *$ & $3.39(2.05,5.64) *$ \\
\hline \multicolumn{5}{|c|}{ Frequency of meal per day } \\
\hline Less than three meals & $27(57.4)$ & $20(42.6)$ & $5.13(2.53,10.37) *$ & $3.97(1.65,9.54) *$ \\
\hline Three meals & $168(39.9)$ & $253(60.1)$ & $2.52(1.62,3.95) *$ & $1.86(1.08,3.17) *$ \\
\hline Above three meals & $30(20.8)$ & $114(79.2)$ & 1.00 & 1.00 \\
\hline \multicolumn{5}{|c|}{ Postnatal care follow-up } \\
\hline Yes & $109(33.4)$ & $217(66.6)$ & 1.00 & 1.00 \\
\hline No & $116(40.6)$ & $170(59.4)$ & $1.36(0.98,1.89)$ & $0.69(0.45,1.09)$ \\
\hline Alcohol use by husba & & & & \\
\hline
\end{tabular}




\begin{tabular}{lllll}
\hline Yes & \multicolumn{1}{l}{$72(42.1)$} & $99(57.9)$ & $1.37(0.95,1.97)$ & $\mathbf{2 . 0 2}(\mathbf{1 . 2 5}, \mathbf{3 . 2 4}) *$ \\
No & $153(34.7)$ & $288(65.3)$ & 1.00 & 1.00 \\
Home garden practice & & & \\
Yes & $46(17.7)$ & $241(82.3)$ & 1.00 & 1.00 \\
No & $179(50.9)$ & $173(49.1)$ & $4.82(3.29,7.04) *$ & $\mathbf{5 . 6 5}(\mathbf{3 . 5 1 , 9 . 0 8}) *$ \\
Knowledge of nutrition & & & \\
Poor & $121(45.1)$ & $147(54.9)$ & $1.90(1.36,2.65)$ & $0.19(0.51,1.26)$ \\
Good & $104(30.2)$ & $240(69.8)$ & 1.00 & 1.00 \\
Minimum dietary diversity score & & & \\
Low & $160(52.6)$ & $144(47.4)$ & $4.15(2.91,5.92) *$ & $\mathbf{2 . 9 4}(\mathbf{1 . 8 8 , 4 . 5 7}) *$ \\
High & $65(21.1)$ & $243(78.9)$ & 1.00 & 1.00 \\
\hline
\end{tabular}

COR-Crude Odds Ratio, AOR-Adjusted Odds Ratio, CI-Confidence Interval, ${ }^{1}$ Hosmer and

309 Lemeshow Test (0.86)

\section{DISCUSSION}

311 The findings of this study showed that $36.8 \%$ of mothers developed food insecurity in the study

312 area. This study also identifies the sociodemographic, health service utilization-related and food

313 source-and feeding practice-related factors of food insecurity among mothers. Accordingly, no

314 formal education, alcohol use by husbands, no income-generating activities, no home gardening

315 practice, low minimum dietary diversity score, and meal frequency less than three and three meals

316 only were the significant predictors of food insecurity of mothers.

317 The finding of this study (36.8\%) is consistent with the study conducted in Ambo District (38.4\%)

318 [23]. On the other hand, it is higher than the study conducted in Vietnam (34.4\%) [17], Canada

319 (17\%) [18], Nigeria (31.3\%) [22], and Dedo and Seqa-Chekorsa Districts in Jimma Zone (6.8\%)

320 [27]. However, this finding is much lower than those of studies conducted in India (78.9\%) [11],

321 the Urban Resettlement Colony in North India (77.2\%) [16], Iran (44\%) [19], Malesia (83.9\%) 
322 [15], Tanzania in two seasons (80\% and 69\%) during the long rainy season and immediately after

323 the harvest season [10], South Africa Limpopo Province (53\%) [21], South Africa (91\%) [20],

324 Farta District (70.7\%) [9], Babile District (57\%) [24], Benshangul Gumuz Region (72\%) [26],

325 Shashemene (55.7\%) [25] and Bule Hora District (77\%) [12]. These inconsistencies could be due

326 to the difference in some sociodemographic characteristics of the study participants. Since this

327 study was done in the postharvest season and the other studies have a preharvest season, seasonal

328 variation may be another important factor for the perceived difference.

329 Regarding the predictors of food insecurity of mothers, the odds of food insecurity were nearly

330 two-fold higher among mothers who had no formal education than those who had formal

331 education. This is in line with the study conducted previously in the rural area of Ethiopia (Farta

332 District and Babile District) and South Africa in a community-based setting. [9, 21, 24]. This is

333 because mothers who have no formal education may not have good knowledge to understand how

334 to grow, improve, manage, and produce enough types of farms to sustain the food security status

335 of their households and themselves.

336 Food insecurity was nearly four-fold more common in mothers who had no income-generating

337 activities than in mothers who had income-generating activities. This is similar to the study

338 conducted in Bule Hora District, Babile District, Farta District and Belo-Jinganfoy District [9, 12,

339 24, 26]. This is because mothers who have no income-generating activities (off-farm sources)

340 cannot challenge food insecurity unless they have an additional source of food in the absence of

341 food in the household.

342 Lactating mothers who had husbands who used alcohol were two times more likely to have food

343 insecurity than their counterparts. This is because mothers who have husbands to expense much 
344 money on alcohol drinking will be highly exposed to food insecurity. To date, the association

345 between food insecurity and alcohol use is not supported by previous studies.

346 The odds of food insecurity were six times higher among mothers who had no home gardening

347 practice than their counterparts. Those mothers who had no practice in a home garden in their

348 compound will have a high probability of developing food insecurity. Because they cannot easily

349 access different types of vegetables, fruits, and other important crops in their backyard, in case

350 they cannot prevent temporal food insecurity. To date, it is not supported by previous evidence.

351 The odds of food insecurity were nearly three times more common among mothers who had low

352 minimum dietary diversity scores than mothers who had high minimum dietary diversity scores.

353 This is supported by the study conducted in Tanzania [10]. This is because mothers who had not

354 taken different groups of food indirectly it indicate that they have no good food security status in

355 their household.

356 Regarding the meal frequency of mothers, mothers who had two meals only or below and three

357 meals were four and two times more likely to have food insecurity than those who had four meals

358 and above, respectively. This is consistent with the study done in northwestern Ethiopia [13]. If

359 lactating mothers do not have at least two meals above they usually take, they are highly at risk of

360 developing undernutrition. This directly indicates that food insecurity is the direct cause of

361 malnutrition for mothers and thereby for their children.

362 Thus, the government of Ethiopia, particularly the Ataye District Health Office, should design

363 intervention programs aimed at improving maternal food security status through appropriate food-

364 based approaches for mothers to have good coping strategies. In addition, the district should

365 strengthen nutrition education programs, creating strong multisectoral collaboration targeted at

366 improving the mother's educational status, home gardening practice, income generating activities 
367 and dietary diversity practice. Since food insecurity has multiple factors, a further study with a

368 stronger study design, like prospective cohort study, is needed to identify other independent

369 predictors of food insecurity in mothers in different seasons.

370 Related to the methodological limitations of the study, the cross-sectional study design inhibits

371 any causal inferences between food insecurity and its predictors. This study design cannot generate

372 the temporal relationship between the outcome variable and the correlates.

373 On the other hand, seasonal variation may be one of the limitations of the study since this study

374 was conducted in the postharvest season of Ethiopia. Even if self-reporting and dietary recall are

375 very common and effective means of collecting data in nutrition and epidemiological studies,

376 especially in resource poor countries like Ethiopia, the self-reported nature and a one-month recall

377 of data collection for food insecurity and a 24-hour recall for dietary diversity make the

378 information prone to social desirability bias, reporting bias and recall bias, which underestimates

379 the power of the study. These biases were minimized by probing and giving detail information

380 about the event. Another limitation is that this study uses previous studies that were conducted at

381 the household level with male household head respondents due to the lack of studies conducted on

382 mothers, which may not be the real comparator of this study.

\section{CONCLUSIONS}

384 The prevalence of food insecurity was high among the study participants in the study area. The 385 major predictor factors for this high prevalence of food insecurity were no formal educational 386 status of mothers, alcohol use by husband, no income-generating activities, no home gardening 387 practice, decreased meal frequency, and low minimum dietary diversity score were the significant 388 predictors of food insecurity of mothers. 


\section{Abbreviations}

390 EDHS-Ethiopian Demographic and Health Survey

$391 \quad$ FI-Food Insecurity

392 FAO-Food and Agricultural Organization of the United Nation

393 FANTA-Food and Nutrition Technical Assistant

394 IHRERC-Institutional Health Research Ethics Review Committee

395 HFI-Household Food Insecurity

396 HFIAS-Household Food Insecurity Access Scale

397 UNICEF-United Nation Children's Fund

398 USAID-United States Agency of International Development

399 WHO-World Health Organization

400 Ethics approval: Ethical approval was obtained from the College of Health and Medical Science

401 Institutional Health Research Ethics Review Committee (IHRERC) of Haramaya University. It 402 was dated 15 January 2018 and numbered with Ref C/AC/R/D/897/18. The clear description of 403 the study title, purpose, procedure, duration, possible risks and benefits of the study was explained 404 for each study participant and obtained before informed consent. Then written informed consent 405 was obtained from each respondent before starting the interview.

406 Availability of data statement: The datasets used and/or analyzed during the current study are 407 available from the corresponding author on reasonable request.

408 Competing interests: None declared.

409 Funding: This research received no specific grant from any funding agency in the public, 410 commercial or not-for-profit sectors. 
411 Authors' contributions: LG: Participated in the conception, and design of the study, performed

412 the data collection, performed the statistical analysis and served as the lead author of the manuscript.

413 GE: Participated in the design of the study, revised subsequent drafts of the paper and contributed

414 to the finalization of the manuscript. AB, YA, SD, HA, AT and WA: Assisted in the design of the

415 study, statistical analysis, intellectual and revised subsequent drafts of the manuscript. All authors

416 read and approved the final manuscript.

417 Acknowledgments: We greatly value the support that we have gotten from the Ataye District

418 Health Office, kebeles administrators and health extension workers who provided us the necessary

419 information in the study kebeles. Our great thanks also deserve to our study participants, data

420 collectors, supervisors and language translators for their invaluable contribution to this study.

421 ORCID ID: Lemma Getacher, https://orcid.org/0000-0002-9237-117X

\section{REFERENCES}

423 1. Coates J., Anne S, and Paula B. Household Food Insecurity Access Scale (HFIAS) for

424 Measurement of Food Access: Indicator Guide. 2007. Available at

425 https://journals.plos.org/plosone/article/file?id=10.1371/journal.pone.0199511\&type=printab

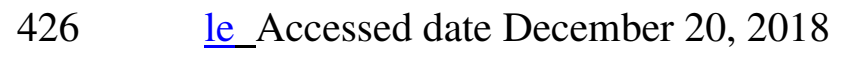

427 2. FAO, and FAD and WFP. The State of Food Insecurity in the World. 2015. Available at 428 http://www.fao.org/publications/sofi/2015/en/ Accessed date December 20, 2018

429 3. Hala G. Food Security and Nutrition in the Context of the Global Nutrition Transition. 2014. 430 Available at https://www.semanticscholar.org/paper/Food-Security-and-Nutrition-in-the431 context-of-the-Ghattas/fa911f068031fe667fe7cd7ae50a0aa12e5d914 Accessed date 432 December 20, 2018 
433 4. Leroy JL, Marie R, Edward AF, et al. Measuring the Food Access Dimension of Food

434 Security : A Critical Review and Mapping of Indicators. Food Nutr Bull. 2015. 36 (2): 16743595. https://doi.org/10.1177/0379572115587274.

436 5. Tarasuk V. Implications of A Basic Income Guarantee For Household Food Insecurity. 2017.

437 Available at https://proof.utoronto.ca/wp-content/uploads/2017/06/Paper-Tarasuk-BIG-EN-

$438 \quad$ 17.06.13-1712.pdf Accessed date December 20, 2018

439 6. Coates J, Anne S, and Paula B. Household Food Insecurity Access Scale (HFIAS) for 440 Measurement of Food Access: Indicator Guide VERSION 3 Washington, D.C.: Food and $441 \quad$ Nutrition Technical Assistance Project, Academy for Educational Development, August 2007. $442 \quad$ Available at

443 https://journals.plos.org/plosone/article/file?id=10.1371/journal.pone.0199511\&type=printab

$444 \quad \underline{\text { le }}$ Accessed date on December 20,2018

445 7. FAO. Regional Overview of Food Security and Nutrition. Addressing the Threat from Climate 446 Variability and Extremes for Food Security and Nutrition. 2018. Accra. 116 Pp. Available at 447 http://www.fao.org/3/a-i7967e.pdf Accessed date December 20,2018

448 8. Mathys E, and Zeina MM. Usaid Office of Food for Peace Usaid Office of Food for Peace 449 Food Security Country $\quad$ Framework. 2019. Available at 450 https://www.fantaproject.org/sites/default/files/resources/FSCF-Madagascar-2013-web.pdf

$451 \quad$ Accessed date December 20,2018

452 9. Endale W, Zelalem BM, Azeb A, et al. Food Insecurity in Farta District, Northwest Ethiopia : 453 A Community-Based Cross-Sectional Study. BMC Res Notes. 2014. 7 (130): 1-6.

454 10. Ntwenya JE, Joyce K, John M, et al. Dietary Patterns and Household Food Insecurity in Rural 455 Populations of Kilosa District, Tanzania. PLoS ONE. $2015.10 \quad$ (5): 1-13. 
456 https://doi.org/10.5061/dryad.qj120.

457 11. Payne HE, Bobbi G, Siena FD, et al.. Factors Associated with Food Insecurity among Women 458 and Children in Rural Rajasthan, India. Journal of Gender, Agriculture and Food Security. 4592016.1 (3): 23-39. https://doi.org/10.19268/JGAFS.132016.2.

460 12. Abdulla AM. Determinants of Household Food Security and Coping Strategies: The Case of 461 Bule-Hora District, Borana Zone, Oromia, Ethiopia. European Journal of Food Science and 462 Technology. 2015.3 (3): 30-44.

463 13. Alem H. Transitory Food Insecurity and Coping Strategies in North-Western Ethiopia 464 Transitory Food Insecurity and Coping Strategies in North-Western Ethiopia. 2014. Available 465 at https://www.researchgate.net/publication/262417159 Accessed date December 20,2018

466 14. Belachew T, David L, Abebe G, et al. Predictors of Chronic Food Insecurity among 467 Adolescents in Southwest Ethiopia : A Longitudinal Study. BMC Public Health. 2012. 12 (1):

468 1. https://doi.org/10.1186/1471-2458-12-604 .

469 15. Ihab AN, Rohana AJ, Wan Manan WM, et al. Association of Household Food Insecurity and 470 Adverse Health Outcomes among Mothers in Low-Income Households : A Cross-Sectional 471 Study of a Rural Sample in Malaysia. J HEALTH POPUL NUTR. 2012.4 (12): 1971-87.

472 16. Chinnakali P, Ravi PU, Deepa S, et al. Prevalence of Household-Level Food Insecurity and Its 473 Determinants in an Urban Resettlement Colony in North India. $J$ HEALTH POPUL NUTR. $474 \quad 2014.32(2): 227-36$.

475 17. Vuong TN, Danielle G, and Rebecca R. Household Food Insecurity, Diet, and Weight Status 476 in a Disadvantaged District of Ho Chi Minh City, Vietnam : A Cross-Sectional Study. BMC 477 Public Health. 2015.15 (232): 1-10. https://doi.org/10.1186/s12889-015-1566-z.

478 18. Orr SK, Naomi D, Lesley F, et al. Relation between Household Food Insecurity and 
Breastfeeding in Canada. CMAJ. 2018190 (11): 312-19. https://doi.org/10.1503/cmaj.170880.

19. Kazemi F, Farnoosh M, Fatemeh SS, et al. Prevalence and Predictors of Food Insecurity among Pregnant Women : A Cross-Sectional Study in Qazvin Province, Iran. Midwifery. 2018. 66: 25-29. https://doi.org/10.1016/j.midw.2018.07.013 .

20. Grobler WC J. Food Insecure Household Coping Strategies: The Case of a Low Income Neighborhood in South Africa. Mediterr J Soc Sci. 2014. 5 https://doi.org/10.5901/mjss.2014.v5n13p100 .

21. Cock ND, MD Haese, N Vink, et al. Food Security in Rural Areas of Limpopo Province, South Africa. Food Sec. 2013. 5: 269-82. https://doi.org/10.1007/s12571-013-0247-y .

22. Olayiwola S, and Yuniyus DG. Analysis of Food Security Status And Coping Strategies Among Rural Households in Oluyole Local Government Area of Oyo. FUW Trends in Science \& Technology Journal. 2017.2 (1): 28-32.

23. Zerihun E, Gudina E, and Firehiwot M. Under Nutrition and Its Associated Factors among Lactating Mothers in Rural Ambo District, West Shewa Zone, Oromia Region, Ethiopia. East African Journal of Health and Biomedical Sciences. 2016.1 (1): 39-48.

24. Bimerew TG, and Fekadu B. Factors Influencing Rural Household Food Insecurity : The Case of Babile District, East Hararghe Zone. J. Dev. Agric. Econ. 2014. 6 (4): 149-58. https://doi.org/10.5897/JDAE12.154.

25. Mitiku A, Bekabil F, and Beyene T. Empirical Analysis of the Determinants of Rural Households Food Security in Southern Ethiopia : The Case of Shashemene District. Basic Res. J. Agric. Sci. Rev. 2013.1 (6): 132-38.

26. Guyu FD, and W Muluneh. Determinants of Seasonal Food Insecurity in the Green Famine 501 Belt of Ethiopia: The Case of Households in Belo-Jiganfoy District, Benishangul-Gumuz 
502 Region. African Journal of Food Science. $2016 . \quad 10 \quad$ (11): $278-91$. 503 https://doi.org/10.5897/AJFS2016.1434.

504 27. Alemayehu M, A Alemayehu and G Abebe. Factors Associated with Malnutrition among 505 Lactating Women in Subsistence Farming Households from Dedo and Seqa-Chekorsa 506 Districts, Jimma Zone, 2014. Developing Country Studies. 2015.5 (21).

507 28. Deitchle M, B Terri, A Swindale, et al.. Validation of a Measure of Household Hunger for 508 Cross-Cultural Use. Washington, DC: Food and Nutrition Technical Assistance II Project 509 (FANTA-2), AED, 2010: vailable at 510 https://www.fantaproject.org/sites/default/files/resources/HHS_Validation_Report_May2010 $511 \_$_.pdf Accessed on December 20, 2018.

512 29. Hagos S, T Lunde, H Damen, et al. Is the Adapted Household Food Insecurity Access Scale 513 (HFIAS) Developed Internationally to Measure Food Insecurity Valid in Urban and Rural $514 \quad$ Households of Ethiopia? BMC Nutrition. 2015. 1 (2).

515 30. Haileslassie, K., Afework, M. and Meron, G. Feeding practices, nutritional status and 516 associated factors of lactating women in Samre Woreda, South Eastern Zone of Tigray, 517 Ethiopia. Nutrition Journal. 2013.12(28).

\section{$518 \quad$ Figure legend}

519 Figure 1: Food security status of mothers in Ataye District, 2018 
Figures

\section{Food insecurity status}

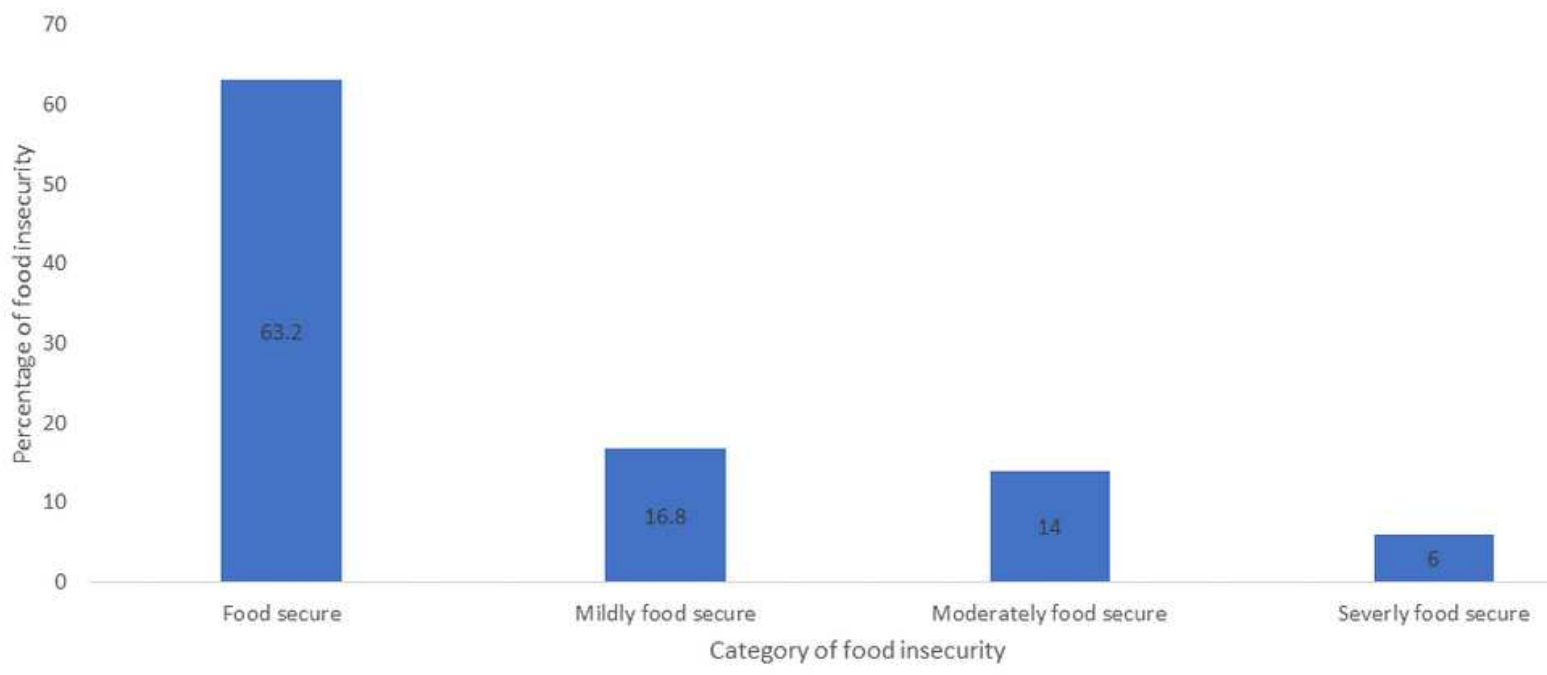

\section{Figure 1}

Food security status of mothers in Ataye District, 2018 